\title{
Komunikacija u zdravstvenom timu
}

\section{Communication in the health care team}

\author{
Anela Ležaić ${ }^{1}$ \\ ${ }^{1}$ Klinički bolnički centar Sestre milosrdnice, Vinogradska cesta 29, 10000 Zagreb \\ ${ }^{1}$ University Hospital Centre Sestre milosrdnice, Vinogradska cesta 29, 10000 Zagreb, Croatia
}

\section{Sažetak}

Dobra komunikacija između medicinskih sestara, liječnika i bolesnika neophodna je za uspješan ishod individualne skrbi za svakog bolesnika. Cilj je da se, uz poboljšanu percepciju timskog rada, medicinske sestre i liječnici osjećaju ugodnije u međusobnoj interakciji i sudjelovanju u zajedničkom odlučivanju. U konačnici je važno i da podržavaju kulturu sigurnosti za bolesnike te članove zdravstvenog tima. Učinkovit zdravstveni tim osigurava medicinskim sestrama manje izgaranja na radnom mjestu. Kvalitetna komunikacija pomaže u organizaciji jasne, točne i dosljedne zdravstvene službe, jamčeći zadovoljstvo bolesnika i zaštitu medicinskih sestara. Komunikacija između članova tima ključna je za postojanje tima. Članovi promiču izražavanje inovativnih prijedloga, korištenje poboljšanih radnih postupaka i jasnu raspravu o problemima i zajedničkim zadacima. Liječnik i medicinska sestra imaju dobro definiran djelokrug rada te djeluju kao partner u zdravstvenom timu.

Najučinkovitiji su timovi oni čiji se članovi razlikuju prema znanju i informacijama koje posjeduju i jedinstveni su u vrednotama koje zagovaraju. Neučinkovit timski rad prepoznat je kao glavni čimbenik koji doprinosi smanjenju sigurnosti bolesnika. Stoga je jačanje timskog rada diljem svijeta ključno za poboljšanje sigurnosti bolesnika.

Potrebno je istaknuti da neučinkovitu komunikaciju između članova zdravstvenog tima opažaju i bolesnici.

U radu su prikazani oblici komunikacije i prednosti timskoga rada. Važnost komunikacije u zdravstvu prikazana je putem dobivenih rezultata provedenih istraživanja drugih autora.

Ključne riječi: komunikacija, tim, zdravstvo, medicinska sestra, bolesnik, liječnik

Kratak naslov: Komunikacija u zdravstvenom timu

\begin{abstract}
Good communication between nurses, doctors, and patients is essential for a successful outcome of individual care for each patient. The main goal of successful communication and improved perception of teamwork for nurses and physicians is to feel more comfortable interacting with each other and participating in joint decision making. It is also very important that they support a culture of safety for patients and members of the health care team. An efficient health care team provides nurses less burnout syndrome in the workplace. Quality communication is a key for organizing a clear, accurate, and consistent health service, guaranteeing patients' satisfaction and the protection of nurses. Communication between team members is necessary to team existence. It is important for members to suggest innovative proposals, the use of improved working procedures, and a clear discussion of problems and common tasks. The doctor and nurse have a well-defined scope of work and they act as a partner in the health care team.

The most effective teams are those whose members differ in the knowledge and information they have and are unique in the values they advocate. Ineffective teamwork has been identified as a major contributing factor to reduced patient safety. Therefore, strengthening teamwork around the world is the key to improving patient safety.

It should be noted that ineffective communication between members of the health care team is also spotted by patients.

The paper presents the forms of communication and the advantages of teamwork. The importance of communication in health care is shown through the obtained results of research conducted by other authors.
\end{abstract}

Keywords: communication, team, health care, nurse, patient, physician

Running head: Communication in health team

\section{Uvod}

Ljudi komuniciraju kako bi se družili, izrazili svoje potrebe, želje i dali oduška svojim emocijama. S kliničkog stajališta osoba koja komunicira je osoba koja nudi pomoć, pokušava smanjiti strah i tjeskobu kod bolesnika, obavještava o događajima i odgovara na potencijalna pitanja [1]. Kvalitetna komunikacija nadilazi ekonomske, socijalne, kulturološke i međusobne razlike te stvara povjerenje, poštovanje i omogućuje sudjelovanje.

Dobra komunikacija vodi prema boljoj zdravstvenoj njezi i boljim međusobnim odnosima. Medicinska sestra mora uspješno održavati međusobne odnose te biti sposobna djelovati unutar interdisciplinarnog i multidisciplinarnog tima. $U$ timskom je radu uspješna i iskrena komunikacija ključna za produktivnu suradnju. Tschannen definira međustrukovno sudjelovanje kao učinkovitu nehijerarhijsku komunikaciju koja se odvija između stručnjaka s različitim znanjima i iskustvima [2]. Svaki član tima doprinosi svojim vlastitim, jedinstvenim pogledom na situaciju. Isti autor tvrdi da su najučinkovitiji timovi oni čiji se članovi razlikuju prema znanju i informacijama koje posjeduju te su jedinstveni u vrednotama koje zagovaraju. Zdravstveni djelatnici suočavaju se s pomanjkanjem znanja o modernim ko- 
munikacijskim vještinama, što se posljedično odražava na timsko sudjelovanje. Stoga često dolazi do pogrešnih, odnosno nepotpunih informacija zbog kojih se može stvoriti loše raspoloženje u timu i smanjena kvaliteta zdravstvene skrbi. Treba istaknuti da neučinkovitu komunikaciju između članova zdravstvenog tima opažaju i bolesnici.

\section{Komunikacija}

Putem komunikacije dobivaju se i pružaju informacije. One su bitan element koji nam omogućuje snalaženje u okolini [3]. Učinkovitost komunikacije ovisi o tome interpretira li primatelj pošiljateljevu poruku na onaj način na koji to pošiljatelj želi.

Nisu svi ljudi jednako važni za naše postojanje, emocije i djelovanje, ali se s mnogima razvijaju važni odnosi. Kvaliteta tih odnosa utječe na duševno stanje, naše raspoloženje i osjećanje, osobni rast i razvoj pa čak i na zdravstveno stanje.

Osoba komunicira gotovo u svakom trenutku, verbalno i/ili neverbalno. $U$ modernom društvu u kojemu dominira sve veća međusobna podjela rada, ljudi postaju sve više ovisni jedni o drugima. Moderan čovjek ne bi mogao živjeti kao izoliran pojedinac, bez kontakata s drugim ljudima.

\section{Razine komunikacije}

Komunikacija se odvija na različitim razinama: od dijaloga između dvije osobe do globalnih socijalnih interakcija između skupina. Standardna je podjela na četiri razine komunikacijskog djelovanja: međusobno komuniciranje, grupno komuniciranje, organizacijsko komuniciranje, komuniciranje u masi. Neki autori, uz navedene, navode komuniciranje unutar sebe i međukulturalno komuniciranje.

Grupno je komuniciranje uobičajen oblik komunikacije u svakodnevnom životu. Namijenjeno je usklađivanju djelatnosti i razmjeni mišljenja, primjerice $u$ radnim skupinama, ali se može raditi i o grupnim susretima te razgovorima između prijatelja i znanaca. Smith i Mounter smatraju da su grupni međusobni susreti (komunikacija) najprimjereniji za posredovanje razne tekuće problematike, što znači da je tada poželjna prisutnost što većeg broja ljudi (zaposlenih) [4].

\section{Osnovni elementi komunikacijskog procesa}

Komunikacija je dvosmjeran proces. Kada se pošalje poruka i primi odgovor, to je jedan komunikacijski ciklus. Sistem komunikacije sastoji se od šest ključnih elemenata: jezik, simboli, poruke, pošiljatelj, primatelj i komunikacijski kanal [3]. Učinkovita međusobna komunikacija je kada primatelj interpretira poruku onako kako je pošiljatelj želio da ju razumije.

Verbalni jezik je čovjekov najvažniji simbolički sustav. Predstavlja sustav komunikacije koji vrijedi za određenu društvenu skupinu i zajednički je za sve njene članove. Govor je najvažnije sredstvo socijalnog utjecaja i djelovanja. Jedna od bitnih značajki verbalnog jezika je kreativnost. Jezik nam omogućuje stvaranje neograničeno mnogo novih fraza, koje su nositelji novih značenja, ideja i saznanja.
Komuniciranje između ljudi predstavlja zajednički skupni simbol sistema poruka, koje se šalju od jednoga do drugoga. Simbolični sustavi su zajednički svim ljudima određene kulture. Simboli su umjetni znakovi u kojima je veza između znaka i onoga što je označeno konvencionalna, dogovorena. Kod simbola se pretpostavlja određeni stupanj shvaćanja njihova značenja kod različitih upotreba istih simbola.

Poruka je bilo koji verbalni ili neverbalni znak u pisanom obliku ili u govoru, ali i u obliku simbola, znaka ili njihova kombinacija. Poruka sadrži informacije koje pošiljatelj želi prenijeti primatelju. Poruka bi trebala biti razumljiva primatelju. Trebala bi biti sažeta, bez umetnutih fraza i viška riječi koje samo opterećuju komunikacijski put. Komunikacijski put je put kojim se poruka prenosi od pošiljatelja do primatelja.

Pošiljatelj je osoba koja poruke oblikuje i emitira. Pri tome bi trebala poštivati temeljna pravila uspješnog komuniciranja.

Komunikacijski kanal je put kojim poruka putuje od pošiljatelja prema primatelju. To mogu biti neposredni kontakti između pošiljatelja, primatelja, pisma i telekomunikacijske veze. U komunikacijskom kanalu nastaju smetnje koje smanjuju učinkovitost prijenosa, ometaju točan i brz prijenos poruka, povećavaju entropiju (neuređenost) prijenosnog sustava.

Za neformalno komuniciranje je značajno da u organizaciji ne mogu kontrolirati niti sadržaj poruke niti komunikacijski kanal kojime će poruka putovati, niti vrijeme prijenosa poruke. Tipičan primjer neformalnog komuniciranja su glasine. Neformalno komuniciranje je intenzivno prije svega onda kada se događaju promjene ili je među zaposlenima prisutan strah.

\section{Osobna prava i dužnosti pri komuniciranju}

Prilikom komunikacije potrebno je poštivati svoja prava kao i prava drugih. To uključuje: ponašanje prema svakoj osobi s poštovanjem, izražavanje svojih emocija i mišljenja, pravo da nas se sasluša i uvažava naše mišljenje, izražavanje svojih potreba i prioriteta, mogućnost odbijanja bez osjećaja krivnje, traženje onog što želimo te pravo reći „ne razumijem".

Potrebno je poštivati i poticati slobodno izražavanje mišljenja i osjećaja ako osjetimo da nečije ponašanje ima negativan utjecaj na nas. Drugima je potrebno pomagati u ostvarivanju učinkovite komunikacije. Svakako je važno biti svjestan svojih dužnosti i u svojem komunikacijskom ponašanju ih poštivati.

\section{Smetnje u komunikaciji}

U svim fazama procesa komuniciranja mogu se pojaviti smetnje koje smanjuju uređenost i povećavaju entropiju [4].

Kod pošiljatelja nastaju smetnje zbog nejasne, dvostruko oblikovane poruke (u poruci se isprepliću važni i nevažni sadržaji) te neprimjereno kodirane poruke (neuređena, dugačka i površna poruka). Smetnja može nastati ako pošiljatelj nema empatičan odnos prema primatelju. 
Smetnje kod primatelja nastaju kada primatelj poruku ne dekodira ili ju dekodira pogrešno; primatelj nema interes za primljenu poruku; poruka se može objasniti na način da odgovara njemu u trenutnoj situaciji; ponekad imamo više poruka istovremeno jer su po sadržaju poruke opsežne i primatelj ih ne može sve dekodirati.

U smetnje na komunikacijskom putu ubraja se: sve što kanal prenosi uz poruku (buka u prostoriji), prekinuti komunikacijski kanal (istovremeno govorenje više osoba) i smetnje koje stupnjuje broj posrednika u komunikacijskom kanalu [5].

\section{Tim}

Postoji velika razvojna razlika između radne skupine i tima. Dok je cilj klasične radne skupine kvalitetan (standardizirani) rutinski rad, cilj tima je kreativan rad. Karakteristike su kreativnog tima: brojnost, uzajamnost i visoka fleksibilnost za praćenje snažnog tempa, brzine učenja te postizanja rezultata. Tim se razvija u smjeru stvaranja karakteristične atmosfere, kolegijalnog prijateljstva, kreativnog entuzijazma i unutarnje kulture koja se temelji na tipičnim vrijednostima, ponašanju, etici i estetici.

Timski rad važan je svugdje gdje zdravstveni djelatnici rade sa zajedničkim ciljevima skrbi za pacijente ili zajednicu. Timski rad podrazumijeva koordiniranu suradnju u skrbi o pacijentima, tako da nema preklapanja, prekida ili pogrešaka, nego uključuje zajedničko rješavanje problema i zajedničko donošenje odluka.

\section{Komunikacija između zaposlenih u timu}

Komunikacija između članova tima ključna je za postojanje tima. Članovi promiču izražavanje inovativnih prijedloga, korištenje poboljšanih radnih postupaka i jasnu raspravu o problemima i zajedničkim zadacima.

Liječnik i medicinska sestra imaju dobro definiran djelokrug rada i djeluju kao partner u zdravstvenom timu. Međutim, ravnopravna uloga sudionika u timu ne isključuje profesionalnu hijerarhiju koja proizlazi iz odgovornosti i jedan je od uvjeta za učinkovito djelovanje tima. Važno je da svaki pojedinac u zdravstvenom timu zna koje su mu zadaće i dužnosti, a isto tako i sposobnosti. To će učiniti tim djelotvornim i služit će osnovnom zadatku - zdravstvenoj skrbi, sigurnom i kvalitetnom pružanju zdravstvenih usluga. Naprotiv, pretjerano isticanje neovisnosti određene profesije može dovesti do neusklađenih postupaka, međusobnih nesporazuma i sloma tima. Za kvalitetnije interakcije u timu važno je međusobno razumijevanje, uvažavanje i slušanje.

U procesu interne komunikacije važnu ulogu imaju odnosi među sudionicima. Odnosi podrazumijevaju količinu i kvalitetu informacija koje zaposlenici imaju. Što više informacija dobiju, manje je sumnje i više uzajamnog povjerenja. U cilju međusobnog razumijevanja potrebno je promicati poštenje, uzajamnu pomoć, sigurnost na radu, ugodnu atmosferu u užoj radnoj skupini, disciplinu na poslu, mogućnost savjetovanja i poštovanja među kolegama [2].

\section{Značaj učinkovite komunikacije u zdravstvu}

U obavljanju svog posla medicinska sestra i liječnik često se susreću s pojedincima u najosjetljivijim razdobljima njihova života kao što su rođenje, bolest, patnja, smrt i druge teškoće koje ugrožavaju život. Stoga je to iznimno osjetljivo područje za rad zdravstvenih djelatnika i nameće se potreba za zahtjevnom komunikacijom između pružatelja zdravstvenih usluga i njihovih korisnika. U zdravstvu se komunikacija odvija između pojedinaca, skupina ili sustava [3].

Odgovarajući opseg i kvalitetan sadržaj poruke temelj su uspješne komunikacije. Poruka mora biti jasna i jednostavna u sadržaju. Pošiljatelj mora moći ponoviti poruku jer primatelj može imati vrlo različitu sposobnost slušanja, primanja, opažanja i tumačenja informacija. Pošiljatelj također mora nastojati naglasiti ono što smatra najvažnijim u komunikaciji, posebno ako očekuje povratne informacije.

$U$ današnje je vrijeme komunikacija bitan dio pružanja zdravstvene zaštite. U zapadnom svijetu komunikacija i stjecanje zajedničkih vještina u području zdravstva dio su obrazovnog programa. Komunikacija je osnova za pružanje zdravstvene zaštite bez obzira na mjesto pojedinca u zdravstvenom sustavu i bez obzira na zanimanje. To podrazumijeva da uspješna komunikacija vodi do boljih i viših standarda pružanja zdravstvene zaštite [7].

Kada se procesi u ustanovi odvijaju u skladu s očekivanjima većine, a većina osoblja obavlja svoj posao na ujednačenoj i visokoj razini, govori se o profesionalizmu. Potrebno je ostvariti više preduvjeta kako bi se postigla profesionalnost. Jedna od bitnih odrednica je da su svi zaposlenici upoznati sa zajedničkim ciljevima i prihvaćaju ih kao svoje ciljeve. Tada su sva očekivanja usmjerena u istom smjeru. Plan za postizanje tih ciljeva postaje zajednička misija i zaposlenici znaju koja je svrha njihova posla. Za dobru i učinkovitu komunikaciju vrlo je važno da zaposlenici dobivaju iste informacije jer samo tako mogu djelovati produktivno kao skupina.

Zdravstveni timovi razlikuju se po sastavu i veličini tima. Neučinkovit timski rad prepoznat je kao glavni čimbenik koji doprinosi smanjenju sigurnosti bolesnika [8, 9, 10]. Stoga je jačanje timskog rada diljem svijeta ključno za poboljšanje sigurnosti bolesnika.

Timski se rad odnosi na skup međusobno povezanih znanja, vještina i stavova koje članovi tima moraju imati kako bi funkcionirali kao tim [11]. Temeljne komponente ovog koncepta uključuju vodstvo, praćenje stanja, ponašanje u radu i komunikaciju $[11,12,13]$. Neke studije usmjerene su na istraživanja razine timskog rada promatrajući ponašanja timova $[14,15,16]$, druge se pak koriste instrumentima kreiranima za praćenje timskog rada [17, 18, 19, 20]. Opservacijske studije timskog rada imaju ograničenja kada se radi o velikom broju pružatelja zdravstvenih usluga. Ankete se učinkovitije mogu upotrebljavati za mjerenje timskog rada u kliničkoj praksi. Međutim, u pregledu anketa o timskom radu utvrđeno je da se konceptualizacija timskog rada i psihometrijskih svojstava značajno razlikuje između instrumenata [21]. Nedavno je razvijen Upitnik za percepcije timskog rada (TPQ) kao dio inicijative za timske strategije i alate u svrhu poboljšanja učinkovitosti i sigurnosti bolesnika 
(TeamSTEPPS) [17, 22]. TPQ obuhvaća način na koji pružatelji zdravstvenih usluga uočavaju trenutno stanje timskog rada: timski rad nije pod utjecajem prethodnog iskustva niti je ograničen na određene odjele ili specijalnosti [17]. Ima široku primjenjivost za različite vrste timova.

Istraživanja percepcije timskog rada među pružateljima zdravstvenih usluga ukazuju na to da razine timskog rada variraju ovisno o radnom mjestu [23, 24]. Na primjer, medicinske sestre koje rade na odjelima intenzivne njege timski su rad ocijenile višom ocjenom nego one koje rade u kirurškim jedinicama [24]. Osim toga, postojale su razlike u dimenziji timskog rada [17, 22]. Studija američkih medicinskih sestara pokazala je da vodstvo tima ima najveći prioritet za poboljšanje [22]. Iz ove perspektive, razine timskog rada mogu se razlikovati ovisno o zdravstvenim sustavima i postavkama. Nadalje, dijagnosticiranje trenutnog stanja timskog rada potrebno je kako bi se poboljšao timski rad na radnom mjestu.

Istraživači su zaključili da timski rad pozitivno utječe na rad osoblja u pogledu sigurnosti bolesnika i ishoda zdravstvene skrbi za bolesnika [10, 25]. Studija devet odjela hitne pomoći utvrdila je da je poboljšan timski rad doveo do značajnog smanjenja stope kliničke pogreške [26]. Ovo smanjenje pogrešaka i štetnih događaja također je zabilježeno u ambulantnoj onkologiji [27] prilikom porođaja [28] i kod kirurških zahvata. [29]. Neadekvatan timski rad medicinskih sestara bio je važan prediktor propuštene sestrinske skrbi [24].

Pokazalo se da su poboljšane percepcije timskog rada medicinskih sestara i liječnika povezane s većim zadovoljstvom i boljim ishodima među hospitaliziranim bolesnicima. Međutim, istraživanja su pokazala da je timski rad medicinskih sestara i liječnika često nedostatan.

\section{Komunikacija između medicinske sestre i bolesnika}

Prema Brinkertu, komunikacija je potrebna ne samo za međusobni prijenos informacija i znanja već i za međusobno povezivanje ljudskih bića svugdje u svijetu [30]. Činjenica da je komunikacija prirodna nenamjerna akcija, gotovo je zanemarena. Papadantonaki je također dodao da je takva pojava nedvojbeno očigledna i u zdravstvenim ustanovama [31]. U većini slučajeva sestrinska profesija usredotočena je na zadovoljavanje zdravstvenih potreba čovjeka, ali prema Lambrini i Loanna, sestrinska praksa zahtijeva ne samo znanje već i dodatnu učinkovitu interpersonalnu komunikaciju, intelektualnu i tehničku sposobnost i vještine [32].

Učinkovite interpersonalne i komunikacijske vještine između pružatelja zdravstvenih usluga i bolesnika jedan su od najvažnijih čimbenika za poboljšanje zadovoljstva pacijenata, usklađenosti i ukupnog zdravstvenog ishoda [33]. Bolesnici prosuđuju medicinske sestre na temelju načina na koji medicinske sestre komuniciraju i odnose se prema njima, a medicinske sestre koje te osjećaje prenose na bolesnike izravno utječu na njihovo zadovoljstvo [34]. Faulkner je tvrdio da je sposobnost učinkovitog komuniciranja prirođena svima [35]. Jasna i ljubazna komunikacija utječe na odgovor bolesnika na zdravstvenu uslugu. Berengere i su- radnici navode da bolesnici koji razumiju pojedinosti svoje bolesti i liječenja, koji uočavaju i vjeruju da je pružatelj zdravstvene usluge zabrinut za njihovu dobrobit, često pokazuju veće zadovoljstvo pruženom skrbi i vjerojatnije je da će slijediti terapiju [33].

Mnogi su komunikaciju definirali kao razmjenu informacija, osjećaja i misli među ljudima. Medicinske sestre pružaju skrb bolesnicima verbalno i neverbalno (pokazivanje, dodirivanje, rad). Informacije mogu biti verbalne ili neverbalne, izgovorene ili pisane, osobne ili bezlične, specifične ili općenite, orijentirane na odnos i tako dalje [36].

Kvalitetna komunikacija pomaže u organizaciji jasne, točne i dosljedne zdravstvene službe jamčeći zadovoljstvo bolesnika i zaštitu medicinskih sestara. Prema Berengereu, dekodiranje poruka ovisi o individualnim čimbenicima i unutarnjim percepcijama [33]. To znači da primateljevo tumačenje onoga što se čuje ne mora biti u skladu s onim što znači pošiljatelju. Vertino također tvrdi da su medicinske sestre odgovorne za zastupanje bolesnih osoba za koje se brinu, koje možda nisu u stanju govoriti ili se zalagati za sebe [37]. Nažalost, mnogi nemaju učinkovite komunikacijske vještine kako bi utjecali, vješto surađivali i zagovarali svoje bolesnike [38].

Istraživanja također pokazuju da medicinske sestre s više godina radnog iskustva imaju visoku tendenciju prakticiranja manje učinkovite komunikacije jer su se navikle na isti način komuniciranja, a da toga više nisu ni svjesne [34]. Stoga postoji stalna potreba za osposobljavanjem i osvješćivanjem s naglaskom na važnosti korištenja učinkovite komunikacijske prakse.

Karakteristike odnosa između medicinskih sestara i bolesnika ovisit će o tome na koji način obje strane razumiju obrazac komunikacije. Da bi se prepoznao neuspjeh, prati se dvosmjerna sposobnost komunikacije koja često dovodi do negativnih generalizacija i stavova, što je rezultat neučinkovite komunikacije [39]. Učinkovita komunikacija nije jednosmjerna. Berengere i suradnici podupiru ovo stajalište u zdravstvenom sustavu u svojoj izjavi da je učinkovita komunikacija dvosmjerni dijalog između bolesnika i pružatelja usluga, ili po definiciji, dvosmjerna cesta gdje oboje govore i slušaju bez prekida, postavljaju pitanja u slučaju nedoumica, izražavaju mišljenja te razmjenjuju informacije, i oboje mogu u potpunosti razumjeti što je onaj drugi rekao. [33]. Dakle, navedeno uključuje interakciju u kojoj svaki pošiljatelj djeluje kao primatelj i obrnuto. Važno je da postoji konsenzus između verbalne i neverbalne komunikacije. Papagiannis dodaje da je najvažnije u stresnim uvjetima vidjeti i razumjeti promjene u neverbalnim porukama bolesnika s kojima se komunicira [34]. U zdravstvenim se ustanovama tijekom provođenja zdravstvene skrbi susrećemo s različitim izborom riječi bolesnika i osobe koja pruža skrb, a to može utjecati na njihovo međusobno razumijevanje. Na primjer, liječnici upotrebljavaju medicinske izraze kako bi precizno i točno prenijeli podatke drugim kliničarima. Međutim, korištenje takvih pojmova u razgovoru s bolesnicima neće biti prikladno jer znanstveni i klinički izrazi mogu biti zbunjujući za pacijente [40]. Istodobno, verbalna komunikacija bolesnika može postati zahtjevna za pružatelje skrbi kada bolesnici komuniciraju na svojim lokalnim dijalek- 
tima, upotrebljavaju nestandardne naglaske i kolokvijalni govor jer to vrlo često otežava razumijevanje poruke.

Prema Lambrini i Loanna, riječi izražavaju samo dio poruke koja se prenosi, dok stav, ton i geste prenose ostatak [41]. Evans je također dodao da je neverbalna komunikacija stalni proces koji se događa bez znanja [42]. Interakciju mogu poboljšati promišljeno slušanje, smiješak i sjedenje $u$ visini bolesnika. Berengere i suradnici navode da većina stilova i interpretacija neverbalne komunikacije ovise o običajima kulture pošiljatelja i primatelja [33].

Medicinske sestre obično preuzimaju vodeću ulogu u brizi za osobe koje su najugroženije kada bolest i drugi nepovoljni uvjeti ne dopuštaju da budu samostalni [43]. Briga i njega čvrsto su povezane. Watson skrb promatra kao odnos čovjeka prema čovjeku gdje jedna osoba (medicinska sestra) utječe na drugu osobu i druga osoba (bolesnik) utječe na nju [44]. U skladu s time, Casey i Wallis [45] predložili su da se veći naglasak stavi na razvoj djelotvornog odnosa među sestrinskim vještinama kako bi se postigao koncept "skrbi orijentirane na bolesnika" koji doprinosi poboljšanju skrbi.

Odnos liječnik - medicinska sestra - bolesnik, definira se kao profesionalni i terapeutski oblik interakcije koji jamči prioritet bolesnicima, a medicinska sestra preuzima odgovornost za uspostavljanje i održavanje granica s bolesnicima. Nesumnjivo, medicinska sestra ima određen stupanj moći nad bolesnikom što joj u određenoj mjeri omogućuje: određivanje svrhe medicinskih intervencija planiranih za pojedinog bolesnika, upravljanje okolinom i kontrolu informacija [46]. Nejednakost moći izlaže bolesnika položaju ranjivosti i ovisnosti, što često dovodi do sukoba. Postoji potreba za razmatranjem socijalnih obilježja pošiljatelja i primatelja komunikacije, kao i strukturne moći odnosa između uključenih komunikatora. Unatoč postojanju neizbježne nejednakosti, osiguravanje učinkovite komunikacije s bolesnikom kako bi se postigao optimalan rezultat skrbi, odgovornost je medicinske sestre.

Briga i komunikacija nerazdvojno su povezane. Ne može se učinkovito komunicirati ako ne postoji briga za osobu koja će primiti skrb [46]. Kako bi se djelotvorno brinula za bolesnika, medicinska sestra mora najprije biti svjesna sebe, izvršiti samoevaluaciju i procijeniti razinu svojih komunikacijskih vještina. Groves navodi da je nemoguće da osoba s niskim samopoštovanjem daje nadu drugima te da je samoevaluacija, iako osnovna, u radu često zanemarena [47].

\section{Zaključak}

Komunicirajući učinkovito i radeći s liječnicima kao tim, medicinske sestre mogu davati ideje za intervencije te konstruktivno zagovarati potrebe bolesnika. Formiranjem timova medicinska sestra - liječnik, poboljšava se komunikacija i timski rad među članovima. Trenutno se mijenja povijesna hijerarhijska struktura medicinskih sestara i liječnika.

Cilj je da se uz pozitivnu percepciju timskog rada koji uključuje liječnike i medicinske sestre, obje skupine osjećaju ugodnije u međusobnoj interakciji i sudjelovanju u zajedničkom odlučivanju. Konačno, kvalitetnijom se komunikacijom pruža veća sigurnost za bolesnike i članove zdravstve- nog tima. Nadalje, medicinske sestre koje blisko surađuju s liječnicima i sudjeluju u zajedničkom odlučivanju, doživljavaju manje izgaranja.

Učinkovita komunikacija ostaje ključan čimbenik u poboljšanju međuljudskih odnosa, skrbi za bolesnika te poboljšanju kvalitete oporavka bolesnika. Učinkovita komunikacija zahtijeva razumijevanje bolesnika i njihovih osjećaja, stoga je za učinkovitu komunikaciju nužno svladavanje komunikacijskih vještina. Jednostavne geste pružatelja skrbi, kao što su topli pozdravi i/ili promišljeno pitanje, često mogu pomoći bolesniku u olakšavanju i osnaživanju komunikacije. Takve geste pružatelja skrbi ne zahtijevaju velik napor, a mogu dati značajne rezultate. U konačnici, važno je da su svi pružatelji skrbi svjesni poruka koje se prenose verbalnim i neverbalnim oblicima komunikacije.

\section{Nema sukoba interesa}

Authors declare no conflict of interest

\section{Literatura/References:}

[1] Chant S, Jenkinson T, Randle J, Russell G. Communication skills: some problems in nursing education and practice. Journal of Clinical Nursing. 2002; 11 (1): 12-21.

[2] Tschannen D. The effect of individual characheristics on perceptions of collaboration in the work environment. Medsurg Nursing. 2004; 5: 312-18.

[3] Vydelingum V. Nurses' experiences of caring for South Asian minority ethnic patients in a general hospital in England. Nursing Inquiry. 2006; 13 (1): 23-32.

[4] Smith L, Mounter, P. Effective internal communication. London: Kogan Page; 2005.

[5] Aarva P, de Haes W, Visser A. Health communication research. Patient Education and Counseling: 2007; 30: 1-5.

[6] Thill JV, Bovee CL. Excellence in Business Communication. Pearson prentice Hall. 2005; 6: 12-14.

[7] Sheldon LK, Barrett R, Ellington L. Difficult Communication in Nursing. Journal of Nursing Scholarship.2006; 38 (2): 141-47.

[8] Joint Commission. Sentinel event data: root causes by event type 2004-2012. Dostupno:http://www.jointcommission.org/assets/1/18/ Root_Causes_Event_Type_04_4Q2012.pdf Datum pristupa: 10.05.2019.

[9] Kohn L.T., Corrigan J.M., Donaldson, M.S. To err is human: building a safer health system. National Academy Press, Washington, DC; 2000.

[10] Manser T. Teamwork and patient safety in dynamic domains of healthcare: a review of the literature. Acta Anaesthesiol Scand. 2009; 53: 143-51.

[11] Salas E, Sims DE, Burk C.S. Is there a big 5 in teamwork?. Small Gr Res. 2005; 36: 555-99.

[12] Alonso A, Baker D.P, Holtzman A, Day R, King H, Toomey L. et al. Reducing medical error in the military health system: how can team training help?. Hum Resour Manag Rev. 2006; 16: 396-415.

[13] Baker D.P, Day R, Salas E. Teamwork as an essential component of high-reliability organizations. Health Serv Res. 2006; 41: 1576-98.

[14] Cooper, S., Cant, R., Porter, J., Sellick, K., Somers, G., Kinsman, L. et al. Rating medical emergency teamwork performance: development of the Team Emergency Assessment Measure (TEAM). Resuscitation. 2010; 81: 446-52.

[15] Hull, L., Arora, S., Kassab, E., Kneebone, R., and Sevdalis, N. Observational teamwork assessment for surgery: content validation and tool refinement. J Am Coll Surg. 2011; 212

[16] Steinemann, S., Berg, B., DiTullio, A., Skinner, A., Terada, K., Anzelon, K. et al. Assessing teamwork in the trauma bay: introduction of a modified "NOTECHS" scale for trauma. Am J Surg. 2012; 203: 69-75.

[17] Battles, J. and King, H.B. TeamSTEPPS Teamwork Perceptions Questionnaire (T-TPQ) Manual [Internet]. ([Accessed 2012 Sep 14]. Available from: American Institutes for Research, Washington, DC; 2010.)

[18] Castner, J. Validity and reliability of the Brief TeamSTEPPS Teamwork Perceptions Questionnaire. J Nurs Meas. 2012; 20: 186-98. 
[19] Kalisch, B.J., Lee, H., and Salas, E. The development and testing of the nursing teamwork survey. Nurs Res. 2010; 59:42-50.

[20] Lurie, S.J., Schultz, S.H., and Lamanna, G. Assessing teamwork: a reliable five-question survey. Fam Med. 2011; 43: 731-34.

[21] Valentine, M.A., Nembhard, I.M., and Edmondson, A.C. Measuring teamwork in health care settings: a review of survey instruments. Med Care. 2014; 1-15.

[22] Castner, J., Foltz-Ramos, K., Schwartz, D.G., and Ceravolo, D.J. A leadership challenge: staff nurse perceptions after an organizational TeamSTEPPS initiative. J Nurs Adm. 2012; 42: 467-72.

[23] Kalisch, B.J. and Lee, K.H. Nursing teamwork, staff characteristics, work schedules, and staffing. Health Care Manage Rev. 2009; 34: 32333.

[24] Kalisch, B.J. and Lee, K.H. The impact of teamwork on missed nursing care. Nurs Outlook. 2010; 58: 233-41.

[25] Reader, T.W., Flin, R., Mearns, K., and Cuthbertson, B.H. Developing a team performance framework for the intensive care unit. Crit Care Med. 2009; 37: 1787-93.

[26] Morey, J.C., Simon, R., Jay, G.D., Wears, R.L., Salisbury, M., Dukes, K.A. et al. Error reduction and performance improvement in the emergency department through formal teamwork training: evaluation results of the MedTeams project. Health Serv Res. 2002; 37: 1553-81.

[27] Bunnell, C.A., Gross, A.H., Weingart, S.N., Kalfin, M.J., Partridge, A., Lane, $\mathrm{S}$. et al. High performance teamwork training and systems redesign in outpatient oncology. BMJ Qual Saf. 2013; 22: 405-13.

[28] Mann, S., Marcus, R., and Sachs, B. Lessons from the cockpit: how team training can reduce errors on L\&D. Contemporary OB/GYN. 2006; 51: 34-45.

[29] Neily, J., Mills, P.D., Young-Xu, Y., Carney, B.T., West, P., Berger, D.H. et al. Association between implementation of a medical team training program and surgical mortality. JAMA. 2010; 304: 1693-700.

[30] Brinkert, R. A literature review of conflict communication causes, costs, benefits and interventions in nursing. Journal of Nursing Management.2010; 18: 145-56.

[31] Papadantonaki, A. Communication and Nursing. Nosileftiki. 2006; 45 (3): 297-98

[32] Lambrini, K, Loanna, V.P. Communication in Nursing Practice. Professional Paper. Mater Socio-med. 2014; 26 (1): 65-7.
[33] Berengere DN, Lori DB., Orlando H, Julia R. Debra R. Improving Interpersonal Communication Between Health Care Providers and Clients: Quality Assurance Methodology Refinements Series. Quality assurance Project; 1997.

[34] Papagiannis, A. Talking with the patient: fundamental principles of clinical communication and announcement of bad news. Medical Time Northwestern Greece. 2007; 6: 43-9.

[35] Faulkner, A. Effective Interaction with Patients, 2nd edn. Churchill Livingston. London: 1998.

[36] Sheldon, L. K. Establishing a Therapeutic Relationship Communication for Nurses: Talking with Patients (third edition). Jones \& Bartlett Learning: 2013.

[37] Vertino, KA.Effective Interpersonal Communication: A practical Guide to Improve Your Life. OJIN: The Online Journal of Issues in Nursing: 2016; 19

[38] Pines, E. W., Rauschhuber, M. L. and Norgan, G. H., Canchola, L., Richardson, C. and Jones, M.E. Stress resiliency, psychological empowerment and conflict management styles among baccalaureate nursing students. J Adv Nurs.2012; 68 (7): 1482-93.

[39] Moussas G I, Karkanias AP, Papadopoulou AG. Psychological dimension of cancer genetics: Doctor-Patient communication. Psychiatric. 2010; 21: 148-57.

[40] DiPrete B. Lori I, et al. Training in Interpersonal Communication: An Evaluation of Provider Perspectives and Impact on Performance in Honduras; Quality Assurance Project, Bethesda, MD. 1995.

[41] Lambrini K, Loanna V. Communication in Nursing Practice. Professional Paper. Mater Socio-med.2014; 26 (1): 65-7.

[42] Evans, RG. Patient centered medicine: reason, emotion, and human spirit? Some philosophical reflections on being with patients. Med Humanit. 2003; 29 (1): 8-14.

[43] Carter, M.A. Trust, power, and vulnerability: a discourse on helping in nursing. Nursing Clinics of North America; 2009; 44: 393-40.

[44] Watson, J. Nursing: Human science and human care, 3rd edition. New York: National League for Nursing.1998.

[45] Casey, A. and Wallis, A. Effective communication: Principle of Nursing Practice E. Nursing Standard; 2011; 25 (32): 35-7.

[46] Crawford, P. et al. Communicating Care. Cheltenham, Stanley Thornes: 1998.

[47] Groves, W. Professional Practice skills for nurses. Nursing Standard. 2014; 29 (1): 51-9. 